\title{
Exploration of Distance Education Mechanical Engineering Experimental Teaching Model
}

\author{
Gangjun Zhai, Lei Xu \\ School of Continuing Education, Dalian University of Technology, Dalian 116011, China \\ network3@dlut.edu.cn
}

\begin{abstract}
The article introduces and discusses the mechanical experimental teaching model under the condition of the modern distance education. Aimed at mechanical engineering experimental model exploration based on the distance education, according to the characteristics of distance education students and the principle of mechanical engineering experimental teaching, combining with the computer multi-media technology, simulation, virtual instrument technology and remote control technology, distance teaching platform, which meet mechanical engineering experimental teaching has been constructed.

Index Terms - Distance Education, Mechanical Experiment, Teaching Mode.

\section{The Position of Mechanical Experimental Teaching In the Modern Distance Education}

The emergence and development of modern distance education is always connected together with all the development of information technology. It is very significant that the modern distance educations provide more opportunities for learning, expands the scale of teaching, improves the teaching quality and reduce the cost of teaching. As an important content of the modern distance education in the major of mechanical, experimental teaching not only need to pay attention to the professional ability, theory and practical combined with the cultivation of ability stressed by the traditional education, but also need more to pay attention to students in the modern education technology environment, improve their ability, which adapt to the needs of social development and continuous learning and exploration, and train the talents who have the innovation spirit and innovation ability. ${ }^{1}$

With the rapid development of the modern distance education, contradictions which restrict machinery experimental teaching become more extrusive. Contradiction between theoretical teaching and the inherent mode of experimental teaching; Contradiction between large scale, large number of students and the specific experiment teaching; Contradiction between weakness foundation of student, big ability difference and the unity plan of experiment teaching; Contradiction between mechanical professional discipline involved with multidisciplinary, and the backward of experimental

equipment, lack of network experiment teaching software. In addition, the implementation and the evaluation of the experiment are still in a traditional education range, lack of innovation and features, and the deficiency of the capital and the lack of teachers are also greatly restricted the development of the modern distance education mechanical experiment teaching.

Therefore, with computer network technology, it is an inevitable trend for the development of the modern distance education to speed up the construction of experimental teaching platform. The modern distance education mechanical experiment teaching limited by funds, personnel, equipment, and many other factors, the type and depth of experiment are poor to the ordinary university. With the development of the modern distance education and the expand requirements of education, the reform of mechanical model of experimental teaching is extremely urgent.

\section{The Mechanical Experiment Teaching Principles of Distance Education}

The idea of mechanical experiment teaching mode building, on the premise of education law, adhere to the student-centered, divide different stages, taking a variety of forms to cultivate students' autonomous learning ability and the comprehensive quality, and improve the students' application ability and innovative consciousness. ${ }^{2}$

\section{A. Arrange Experimental Teaching Activities adhering to the Student-centered}

Experimental teaching is an important link of the mechanical professional teaching process, according to the professional training target; experimental teaching is a transition process from theory to experiment, from the abstract to specific, under the teacher guidance. The experimental teaching activity contained in mechanical professional must adhere to the principle, which take students as the center, and take the student's study as the center, improve the students' abilities as the center.

\section{B. Dividing Different Stages, Improve Students' Comprehensive Ability Step by Step}

According to the teaching plan, experiment teaching can be divided into some stages, so that students can accumulate knowledge and improve skills constantly in the area of modern machinery manufacturing technology.

C. To Take a Variety of Forms for Experimental Teaching, in the Process of Developing Experimental Teaching Resources

According to the characteristics of each mechanical experiment teaching, make full use of network education technology methods, and use various forms to teach. A variety 
of the experimental teaching mode can make the experiment teaching more novelty and more effectiveness, which make students produce strong desire to participate in the experiment, increase their awareness of learning and interest in the meanwhile, because of the new method and technology application.

\section{Implementation of Modern Distance Education Mechanical Experiment Teaching}

With the rapid development of the modern distance education, mechanical experiment must also adapt to the needs of the development of the modern distance education. In order to guarantee the feasibility of the modern distance education experiment, ensure the teaching quality of the experiments course, ensure the experiment teaching plan to be completed, and achieve teaching purpose of the modern distance education experiment, the multimedia courseware demonstration, the simulation experiment, virtual experiment, remote control experiment etc. can be used.

\section{A. Using Multimedia Courseware Demonstration Experiment}

The experimental courses teachers of the modern distance education could organize experiment aim, experiment content and experimental steps by using the form of courseware in some experiment, witch make students have experience personally feeling. Through the multimedia courseware demonstration experiment, students can obtain the intuitive, image of the teaching effect to observe and operate by courseware, finish the experiment process, and deepen the understanding of theoretical knowledge.

\section{B. Using Simulation Experiment Software}

By using simulation experiment software, students do simulation experiment by computer, which can not only cultivate the students' theoretical research ability, but also strengthen students' practical skills.

The simulation experiment adopts the method of virtual instruments and equipment, simulates real experiment equipment such as instrument, equipment and components by computer software, the server shares simulation software platform of the local virtual laboratory, students can combine connection according to the requirements and virtual experimental instruments provided in virtual laboratory. The whole system does not involve the concrete experimental instrument hardware, just use software to simulate experiment, to accomplish realize the sharing of the experimental data. ${ }^{3}$

The simulation experiment by using computer hardware and simulation software, witch forms the function that ordinary instrument have and other special function that ordinary instrument do not have. The software platforms show the function of the computer data processing and rich images display greatly. For example, Labview software is the application software, which combines the virtual instrument technology and network technologies developed by U.S. national company. Users can write a strong function of Labview application software, to build the simulation experiment platform, and call this simulation platform through the Web page form for network learners' learning. Figure 1 shows remote access principle diagram of network laboratory simulation experimental platform. Based on the network function of the virtual instrument, it realize the experiment teaching with interaction and real-time network effect, on the one hand, solving the lack of experiment field, experiment equipment and insufficient teaching funds, on the other hand, virtual experimental environment for network learners, so that learners could watch the experiment unlimited by time, avoid the dangers of the real operation, increase students' experiment interest, and improve the efficiency of the experiment. ${ }^{4}$

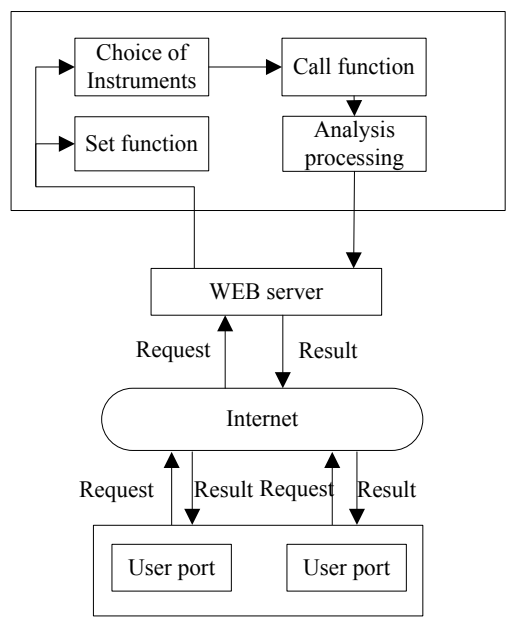

Fig.1. Remote Access Principle Diagram of Network Laboratory Simulation Experimental Platform

\section{Using Virtual Reality Technology to Virtual Experiment}

The physical simulation experiment can be done with computer network teaching platform, which provided by virtual laboratory. Virtual Reality technology makes use of 3D graphics generation technology, sensing interactive technology and high resolution display technology, produces the 3D realistic Virtual environment. By using various sensors and visual equipment, visual, auditory and tactic role are acted to the user, and the user can integrate into this special environment, to perceive and operate object and control the environment in the Virtual world, becoming a member of the Virtual environment, so as to gain immersive feel and experience, which has the characteristics of immersion or onthe-spot participation, interaction, artificial reality or imagination and etc. Virtual experiment system structure is shown in figure 2.

Using the virtual reality technology to perform some system structure and dynamic, to provide students with a kind of the environment, which can be experienced and observed by themselves. Reality experiment environment can be simulated by the computer, teachers or students do some kinds of experiments accurately on computer, including the experiment that is impossible to do in the real environment, achieve effect that the real experiment cannot be achieved, and avoid all kinds of danger in real experiment or operation. The 
virtual experiment has the characteristics such as simple and easy to operate, the effect is real and etc. The virtual reality technology can also simulate various hypothetical virtual models, which are proposed by students in the learning process, and observe the result of a hypothesis through the virtual system.

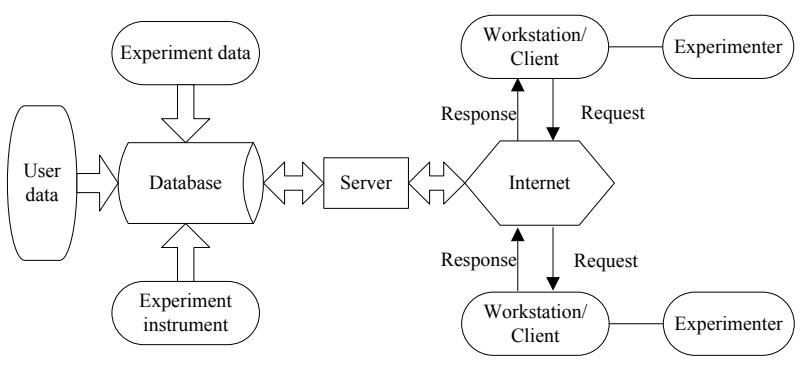

Fig.2. Virtual Experiment System Structure

\section{Remote control experiment}

The remote control experiment is the real experiment in different places of process completed by the Internet remote operation of the laboratory instruments. With inside or outside computer connected into Internet, remote control experiment is finished by real-time controlling of the laboratory instrument and adjusting experimental parameters, observing the experiment phenomenon, giving feedback to the operator of the real-time and dynamic experimental results, and transferring the scene of the laboratory to remote students through the camera. Students complete the man-machine interactive experimental process in the remote laboratory, which should be done personally in real laboratory formerly, and realize the real process of the instrument regulation and experimental operation. This kind of experiment requires that the laboratory should meet the requirement of laboratory equipment of remote control experiment, and each device instrument must have the digital port to realize the remote control.

Remote control experiment which is not limited by time and space, increases the flexibility of teaching, and expand the experimental teaching method, improve the experimental instruments including the utilization of valuable equipment, and eases the conflict of the lack of experimental teaching resources. At the same time, because remote control experiment unlimited by space, students of different universities or different campus needs not to travel long distant to laboratory for experiments, and students of the adult education can also complete the course of experiment by choosing non-work time at home or work unit.

The hardware structure of the remote control experiment is shown as figure 3 , it consists of five parts: the remote user, the field control computer, the Internet, teaching equipment and server (database, Web, video and Matlab, etc.). The remote control laboratory provides an experiment and communication platform for the teachers and students to study, research and innovate. This kind of laboratory mode based on Web can provide a large number of the parameters feedback, which contains the experimental results and important information to users. It also allows the user to perform the visual surveillance operation and control the network. Due to the control algorithm and the database consume system resources, only one server is hard to meet the service requirements, and each teaching equipments should use a fixed PC as a controller. All of the servers in the remote control laboratory together form a server cluster. Students can visit the laboratory just through the Web server.

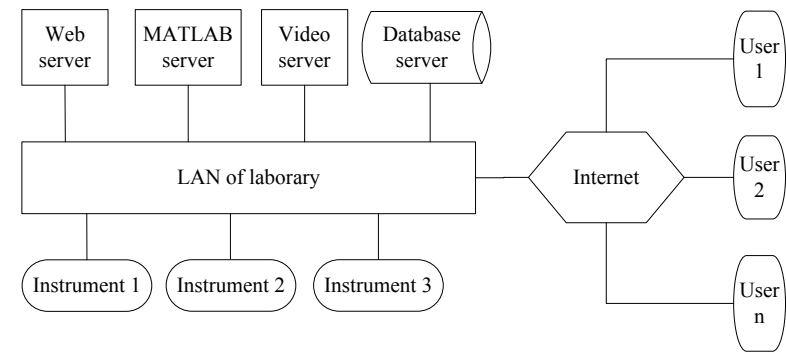

Fig. 3. The Hardware Structure of the Remote Control Experiment

\section{The Explorations of the Modern Distance Education Mechanical Experiment Teaching Mode Construction}

The modern distance education mechanical experiment teaching arranges experiment content progressively according to professional planning, professional characteristics and the development trend of the experimental teaching. Based on the law of cognition, from simple to complex, from individual units to comprehensive application, to set experiments hierarchically, and form distinctive multilayer experimental teaching system. Combining with the teaching request, the whole experiment teaching contents could be divided into multi-level module partition, in order to meet students' various stages of learning needs in different professional and different levels. According to the stages of mechanical experiment learning, it can generally be divided into: basic experiment, professional basic experiment and innovative experiment. According to the different experiment types using relevant technology, it can fully utilize the advantage of network education, and adapt to the requirements of the development of the modern distance education.

\section{A. The Form of Courseware Demonstration Experiment Used in Mechanical Basic Experiment}

Mechanical basic experiment related with the basic skill experiment and theory course, depends on mechanical basic experiment platform and engineering training platform, takes enhancing the students' basic quality and ability of mechanical as the target, usually uses general demonstration experiment and verification experiment, mainly to introduce knowledge content and the basic skills. This kind of experiment course mainly covers, computer aided design, engineering mechanics, etc. Basic skills experiments include metalworking practice, electrician electron practice, etc.

\section{B. The Form of Simulation and Virtual Experimental Used in The Professional Basic Experimental}


The professional basic experimental course is opened after the student has some theoretical and practical basis. To pay attention to the training of the design of experiments and development ability is helpful students to promote the ability of presenting and solving the question, and sense of accomplishment, to further stimulate their enthusiasm of autonomous learning and innovation design, to promote exchanging knowledge and cooperation between teachers and students, between students and students. In the meanwhile, it is also helpful to cultivate innovation ability and team spirit of the students. In the professional basic experiment course, according to the characteristics of mechanical discipline, the simulation and virtual experimental form can be used to rich experiment content, and improve the students' enthusiasm. For example, the structure of the machine, $\mathrm{CNC}$ processing, etc. Because other means do not vivid enough, the virtual reality technology can be used to make students manipulate machine and machining tools virtually, etc. This kind of experiment course mainly covers as follows, mechanical design, mechanical principle, mechanical manufacturing, hydraulic and pneumatic transmission, etc.

VERICUT is professional virtual CNC processing software developed by CGTECH Company. Different from general CAM software which only simulates the tool path or intermediate file, VERICUT can not only simulate CNC machining terminal code ( $\mathrm{G}$ code), but also realize virtual visualization such as physical machine, fixture, tools, blank, which included in complete processing environment. VERICUT for virtual machining system diagram is shown as Figure 4.

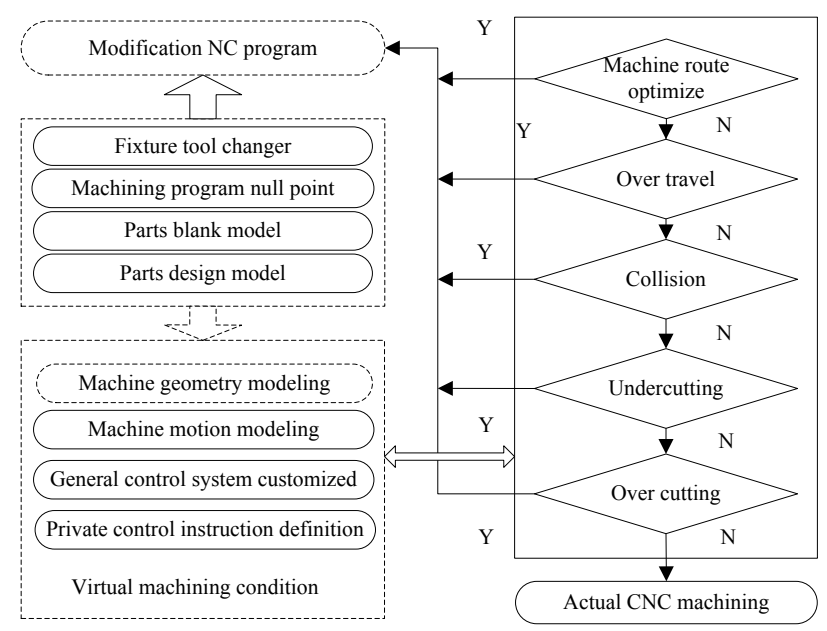

Fig. 4. Virtual Machining System Diagrams

\section{Remote Control Experiment Used in Professional Experimental Course}

Professional experimental course which is based on the basic experiment and professional basic experiment has comprehensive training on higher levels of exploration and practice to make the students entered into the scientific research and production practice as soon as possible. Professional experiments courses use remote control experiment, to make the student consolidate and develop the knowledge which has been mastered in, carry out the experiment of new technology, new method and new means, and constantly improve the students ability and integrated quality from participating in the scientific research in the open the experimental environment. ${ }^{5}$

\section{Conclusions}

Faultless teaching mode which is the foundation of promoting the rapid development of network education, makes use of multimedia courseware, the computer simulation, the virtual technology, to construct network experimental teaching platform, and solve the problems of the resources and the practice learning of the modern distance education mechanical experiment teaching. At present, the network experiment technology is still in the initial stage, there are many practical problems to be solved. Under the guidance of the principle of higher education machinery network experiment teaching, improving and developing network experiment teaching resources, and building up the system of network experimental teaching, could adapt to the needs of constantly development of the modern distance education. Deepening reform of the experimental teaching system is still a long-term and arduous task. And the next step, it is important to further explore and improve the construction of experimental teaching system combining with the characteristics of the distance education and student's actual situation.

\section{References}

[1] JuShan Dou, The exploration of Contemporary and Distance Education Engineering Practice Teaching mode, China Adult Education, (2008).

[2] ZhongSheng Wang, Lei Zhang, Research on VERICUT-Based Virtual Simulation of Turning-Milling Machining Center, Aeronautical Manufacturing Technology, (2011).

[3] MingZhou Du, ChunSheng Liu, ShaoJie Zhang, Design of Web-based Remote Control Laboratory Platform, Journal of Electrical \& Electronic Education, (2011).

[4] BuWei Ye, DeJun Ma, Virtual Experiment Technology and Application in the Application of Remote Education, Continue Education Research, (2011).

[5] Chen Ma, YanHong Meng, ZhiXian Cao, The Exploration of Constructing Mechanical Experiment Teaching System in University, Laboratory Science, (2010). 